\title{
Excitatory Amino Acid Release and Free Radical Formation May Cooperate in the Genesis of Ischemia-Induced Neuronal Damage
}

\author{
Domenico E. Pellegrini-Giampietro, Giovanna Cherici, Marina Alesiani, Vincenzo Carla, and Flavio Moroni \\ Dipartimento di Farmacologia Preclinica e Clinica "Mario Aiazzi Mancini" Universitá di Firenze, 50134 Firenze, Italy
}

\begin{abstract}
Excessive stimulation of excitatory amino acid (EAA) receptors and abnormal production of oxygen-derived free radicals have repeatedly been implicated in the series of events linking brain hypoxia or ischemia to neuronal death. We report here that in rat hippocampal slices the $\mathrm{KCl}-\mathrm{stim}$ ulated output of labeled $\mathrm{D}-{ }^{3} \mathrm{H}$ aspartate or of endogenous aspartate and glutamate significantly increased under in vitro simulated hypoxic, hypoglycemic, or ischemic conditions. In particular, when the slices were incubated for 10 min at $32^{\circ} \mathrm{C}$ under "ischemic" conditions (namely, lack of oxygen and glucose), endogenous aspartate and glutamate in the supernatant increased by 10 and 20 times, respectively. Since radical scavengers (D-mannitol), drugs reducing free radical formation (indomethacin, corticosteroid), or enzymes able to metabolize them (catalase and superoxide dismutase) significantly reduced this output, it was supposed that free radicals caused EAA release. A direct demonstration of this concept was obtained by showing a significant release of EAA after incubation of hippocampal slices with enzymes and substrates known to cause the formation of free radicals, such as xanthine plus xanthine oxidase or arachidonic acid plus prostaglandin synthase. Neither ischemia nor the enzymatic reactions leading to free radical production increased the activity of the cytoplasmic enzyme lactate dehydrogenase in the incubation medium, thus ruling out a nonspecific cellular lysis. It appears therefore that during ischemic states, brain production of reactive molecules (free radicals) causes an increased output of EAA. This may trigger a series of events which could help to explain the delayed loss of neurons after a transient ischemic period.
\end{abstract}

Formation of large amounts of toxic oxygen-derived free radicals in hypoxic and ischemic brain has been proposed as an important step in the sequence of events that links cerebral blood flow reduction to neuronal death (Demopoulos et al., 1980; Siesjo, 1981; Raichle, 1983; Braughler and Hall, 1989; Hall and Braughler, 1989). Free radical formation has been demonstrated both during the acute ischemic attack (Demopoulos et al, 1980) and when blood and oxygen eventually return to the brain upon reperfusion (McCord, 1985). Certainly, free radical scavengers

\footnotetext{
Received July 17, 1989; revised Oct. 10, 1989; accepted Oct. 16, 1989.

We wish to thank Dr. Renato Corradetti for the electrophysiological controls and helpful discussions. This work was supported by grants from the University of Florence, the National Research Council, Rome, and the Region of Tuscany.

Correspondence should be addressed to Prof. Flavio Moroni, Dipartimento di Farmacologia, Universitá di Firenze, Viale Morgagni, 6550134 Florence, Italy. Copyright (C) 1990 Society for Neuroscience $0270-6474 / 90 / 031035-07 \$ 02.00 / 0$
}

seem to be able to reduce anoxic or ischemic neuronal damage both in vitro and in vivo (Smith et al., 1980; Taylor et al., 1984, 1985; Itoh et al., 1986; Cao et al., 1988; Sasaki et al., 1988).

Another research line that has been thoroughly and independently investigated in order to understand the cause of neuronal damage induced by hypoxic or ischemic states deals with the excitatory amino acids (EAA) aspartate (Asp) and glutamate (Glu), synaptically released transmitters which are endowed with neurotoxic effects (Rothman and Olney, 1986, 1987; Choi, 1988a). An increased release of Glu and/or Asp has been observed both during anoxia in vitro (Bosley et al., 1983; Hauptman et al., 1984) and during cerebral ischemia in vivo (Benveniste et al., 1984; Erecinska et al., 1984; Hagberg et al., 1985; Globus et al., 1988). Furthermore, EAA receptor antagonists have been shown to offer protection against anoxic neuronal death in vitro (Rothman, 1984; Clark and Rothman, 1987; Goldberg et al., 1987) or ischemic brain damage in vivo (Simon et al., 1984; Gill et al., 1987; Andiné et al., 1988; Kochhar et al., 1988). Recently, a reduction in the number of EAA receptors following ischemia has also been reported (Westerberg et al., 1987; Leach et al., 1988).

Our working hypothesis was that these 2 metabolic events, namely, free radical formation and EAA release, are mutually related and cooperate in the series of events that link brain anoxia or ischemia to neuronal death. For this purpose we developed an in vitro model of simulated ischemia, and we studied the EAA release from the hippocampus, a brain region particularly sensitive to hypoxic or ischemic insults (Smith et al., 1984).

\section{Materials and Methods}

Materials. Allopurinol, corticosterone, indomethacin, kynurenic acid (KYN), D-mannitol, o-phthalaldehyde, and xanthine were purchased from Sigma Chemical Co. (St. Louis, MO). Catalase $(65,000 \mathrm{U} / \mathrm{mg}$ protein), lactate dehydrogenase (LDH; $550 \mathrm{U} / \mathrm{mg}$ protein), superoxide dismutase (SOD; $5000 \mathrm{U} / \mathrm{mg}$ lyophilisate), and xanthine oxidase (XOD; $1 \mathrm{U} / \mathrm{mg}$ protein) were from Boehringer Mannheim GmbH (FRG). Arachidonic acid and prostaglandin synthase (PGS) were from Calbiochem Corporation (San Diego, CA). D- ${ }^{3} \mathrm{H}-A s p(10-30 \mathrm{Ci} / \mathrm{mmol})$ was from Amersham (Amity PG, Milan), ethylmercaptan from Fluka AG (Buchs, Switzerland), and 6,7,dinitroquinoxaline-2,3-dione (DNQX) from Tocris Neuramin (Buckhurst Hill, Essex, UK). All other reagents were from Merck (Darmstadt, FRG), analytical grade.

Preparation of rat hippocampal slices and in vitro experimental models. Male Wistar rats (Nossan strain, Milan), weighing 180-200 gm were used. After decapitation, their hippocampi were rapidly removed and plunged into ice-cold Krebs-bicarbonate buffer (in mM: $\mathrm{NaCl}, 122 ; \mathrm{KCl}$, 3.1; $\mathrm{MgSO}_{4}, 1.2 ; \mathrm{KH}_{2} \mathrm{PO}_{4}, 0.4 ; \mathrm{CaCl}_{3}, 1.3 ; \mathrm{NaHCO}_{3}, 25 ;$ and glucose, 10). Transverse slices ( $350 \mu \mathrm{m}$ thick) were cut with a McIlwain tissue chopper from each hippocampus and then left to stand, dipped into Krebs-bicarbonate solution gassed with $95 \% \mathrm{O}_{2} / 5 \% \mathrm{CO}_{2}$ for $2 \mathrm{hr}$ at room temperature in order to allow functional recovery. After this pe- 
Table 1. Excitatory amino acid release in various experimental models

\begin{tabular}{|c|c|c|c|c|c|c|c|c|c|}
\hline \multirow[b]{2}{*}{ Experimental condition } & \multicolumn{9}{|l|}{ Release } \\
\hline & D-3H-Asp & $(\% a)$ & $(\% b)$ & L-Asp & $(\% a)$ & $(\% \mathrm{~b})$ & L-Glu & $(\% a)$ & $(\% \mathrm{~b})$ \\
\hline Control & $14.0 \pm 0.4$ & $(100)$ & & $37.1 \pm 8.6$ & $(100)$ & & $72.6 \pm 15$ & $(100)$ & \\
\hline $50 \mathrm{~mm} \mathrm{KCl}$ & $27.7 \pm 1.7^{a}$ & (199) & $(100)$ & $272.5 \pm 41^{a}$ & (734) & $(100)$ & $1111 \pm 168^{a}$ & $(1530)$ & $(100)$ \\
\hline "Hypoxia" & $14.3 \pm 1.6$ & $(102)$ & & $38.2 \pm 6.6$ & (103) & & $51.1 \pm 9.7$ & $(70)$ & \\
\hline "Hypoxia" + $50 \mathrm{~mm} \mathrm{KCl}$ & $55.5 \pm 5.3^{b}$ & & $(200)$ & $549.2 \pm 41^{b}$ & & $(201)$ & $2835 \pm 310^{b}$ & & $(255)$ \\
\hline "Hypoglycemia" & $12.8 \pm 1.4$ & $(91)$ & & $45.3 \pm 5.3$ & $(122)$ & & $73.5 \pm 10$ & $(101)$ & \\
\hline "Hypoglycemia" + $50 \mathrm{~mm} \mathrm{KCl}$ & $44.4 \pm 3.4^{b}$ & & $(160)$ & $453.5 \pm 54^{b}$ & & $(166)$ & $1622 \pm 180^{h}$ & & (146) \\
\hline "Ischemia" & $24.5 \pm 1.9^{a}$ & $(175)$ & & $395.2 \pm 49^{a}$ & $(1065)$ & & $1465 \pm 135^{a}$ & (2017) & \\
\hline "Ischemia" + $50 \mathrm{~mm} \mathrm{KCl}$ & $63.8 \pm 6.5^{b}$ & & $(230)$ & $835.3 \pm 71^{b}$ & & $(306)$ & $3832 \pm 457^{b}$ & & $(345)$ \\
\hline
\end{tabular}

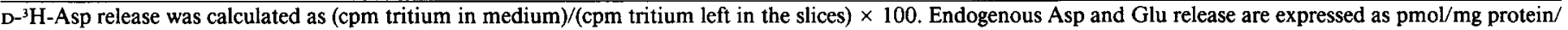

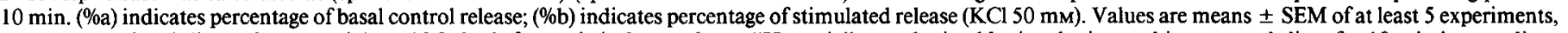

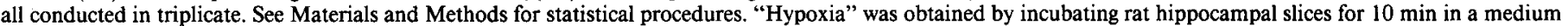
bubbled with $\mathrm{N}_{2}$ instead of $\mathrm{O}_{2}$, "hypoglycemia" by incubation in a glucose-free medium, and "ischemia" by a combination of these 2 conditions.

a $p<0.01$ vs control release.

" $p<0.01$ vs $\mathrm{KCl}$-induced release.

riod, viability was electrophysiologically assessed in some of the slices according to Corradetti et al. (1983), and they were then placed into test tubes ( 5 slices each) containing $650 \mu \mathrm{l}$ of gassed solution at $32^{\circ} \mathrm{C}$, with or without the drugs under study.

In order to simulate ischemic or hypoxic injury to the brain, viable hippocampal slices were incubated in test tubes for $10 \mathrm{~min}$ in glucosefree Krebs-bicarbonate solution saturated with $95 \% \mathrm{~N}_{2} / 5 \% \mathrm{CO}_{2}$ ("ischemia"), while other slices were incubated with glucose-containing buffer bubbled with $95 \% \mathrm{~N}_{2} / 5 \% \mathrm{CO}_{2}$ ("hypoxia") or with glucose-free solution gassed with $95 \% \mathrm{O}_{2} / 5 \% \mathrm{CO}_{2}$ ("hypoglycemia").

When the effects of enzymatically formed free radicals on hippocampal release were studied, the slices were incubated for $20 \mathrm{~min}$ at $32^{\circ} \mathrm{C}$ in Krebs-bicarbonate buffer gassed with $95 \% \mathrm{O}_{2} / 5 \% \mathrm{CO}_{2}$ and containing xanthine plus XOD or arachidonate plus PGS, which are excellent sources of superoxide anion $\left(\mathrm{O}_{2}^{-}\right)$, hydrogen peroxide $\left(\mathrm{H}_{2} \mathrm{O}_{2}\right)$, and hydroxyl radical (OH.) (Kellogg and Fridovich, 1977).

In some experiments, a $50 \mathrm{~mm} \mathrm{KCl-containing} \mathrm{buffer} \mathrm{(with} \mathrm{isomolar}$ reduction of $\mathrm{NaCl}$ ) was utilized, while in others $\mathrm{CaCl}_{2}$ was omitted from the medium and replaced by $1 \mathrm{~mm}$ EGTA.

Studies on $D-{ }^{-} H$-Asp release. For this set of experiments, hippocampal slices were previously incubated for $45 \mathrm{~min}$ at $32^{\circ} \mathrm{C}$ in oxygenated buffer containing $\mathrm{D}^{3} \mathrm{H}$-Asp (final concentration, $50 \mathrm{nM}$ ), then washed for 30 min with fresh solution, and finally transferred into the test tubes (2 slices each) containing one of the different gassed solutions. The experimental reactions were carried out for $10 \mathrm{~min}$ and were then terminated by cooling the test tubes in an ice bath. The supernatant was separated from the slices by gentle filtration on Whatman GF/C filters, and the tritium content of both the supernatant and the solubilized slices, after the addition of an appropriate amount of scintillation fluid, was counted on a Packard (Tri Carb 1500) liquid scintillation analyzer. Labeled release was calculated as (cpm tritium present in the supernatant)/(cpm tritium left in the slices) $\times 100$, and statistical differences were evaluated by performing analysis of variance on overall data and modified $t$ statistics (Wallenstein et al., 1980) on individual comparisons.

Studies on endogenous Asp and Glu release. Hippocampal slices were prepared as described, and 5 of them were kept in each test tube for 10 $\min$ at $32^{\circ} \mathrm{C}$ in the required experimental conditions. After cooling the test tubes in an ice bath, aliquots $(500 \mu \mathrm{l})$ of the supernatant were removed and stored at $-20^{\circ} \mathrm{C}$ for subsequent analysis. Slices were used for protein determination (Lowry et al., 1951).

Endogenous Glu and Asp were measured by HPLC and fluorimetric detection after a precolumn derivatization procedure with $o$-phthalaldehyde and ethylmercaptan (Connick and Stone, 1988). Aliquots (200 $\mu 1)$ of each sample were rapidly mixed with $100 \mu$ l of the derivatizing solution before being injected in the HPLC apparatus. This reaction, which led to the formation of the 1-alkyl-thio-2-alkyl substituted isoindole derivatives of the amino acids, proved to be stable for at least $60 \mathrm{~min}$, giving identical results at different times of injection within this period. Injections of $100 \mu \mathrm{l}$ were made into an HPLC apparatus, consisting of a Perkin-Elmer ISS- 100 autosampler, 2 Perkin-Elmer Series 10 pumps, a Perkin-Elmer Series $20 \mathrm{LC}$ controller, and a Perkin-Elmer
LS3 fluorescence spectrometer with a wavelength of $334 \mathrm{~nm}$ and emission cut-off filter at $426 \mathrm{~nm}$. Separation was performed on a PerkinElmer reversed-phase $\mathrm{C}_{18}$ column $(15 \mathrm{~cm} \times 2.6 \mathrm{~mm}, 5 \mu \mathrm{m}$ particle size) fitted with a $\mathrm{C}_{18}$ "guard pak" precolumn (Waters). Solvent A was $65 \%$ methanol in water, and solvent B was $50 \mathrm{~mm}$ sodium acetate and 50 $\mathrm{mM} \mathrm{NaH}_{2} \mathrm{PO}_{4}$. The gradient program started from $20 \%$ of solvent $\mathrm{A}$ at the moment of injection and reached $80 \%$ in $12 \mathrm{~min}$. Asp and Glu derivatives were identified by their retention times relative to reference injections of standard Asp and Glu, and their concentrations were quantified by comparing sample and reference peak heights. This procedure gave results that were comparable to those obtained with a gas chromatography-mass spectrometer method previously described (Moroni et al., 1981).

Glu and Asp release were expressed as pmol $/ \mathrm{mg}$ protein $/ 20 \mathrm{~min}$, and statistical analysis was carried out as indicated for radiolabeled release.

$L D H$ activity assay. Nonspecific lysis of neuronal cells was studied by detecting the activity of LDH, a typical cytoplasmic enzyme, in the supernatant of slices exposed for $10 \mathrm{~min}$ to the different described procedures, by means of a spectrophotometric assay (Vassault, 1983). A diagnostic kit (No. 228-UV) from Sigma was used, and a reference curve was constructed from LDH standards.

\section{Results}

\section{EAA release under different in vitro experimental conditions}

Table 1 shows that hippocampal slices preincubated with $\mathrm{D}^{-3} \mathrm{H}$ Asp released an increased amount of tritium when incubated for 10 min under ischemic conditions (no glucose, $\mathrm{N}_{2}$ instead of $\mathrm{O}_{2}$ ). This basal outflow was not affected when the slices were incubated under hypoxic or hypoglycemic conditions, and it almost doubled when slices were depolarized with $50 \mathrm{mM} \mathrm{KCl}$; upon depolarization, "hypoxic," "hypoglycemic," and "ischemic" slices displayed a significantly higher efflux of label (Table 1).

Table 1 also shows that endogenous Asp and Glu release were qualitatively affected in the same manner by the different experimental challenges, the only difference being the more pronounced enhancement of basal and stimulated control outflows. Basal Asp and Glu release were increased by 10 - and 20 -fold, respectively, under ischemic conditions, while hypoxia and hypoglycemia alone were ineffective. In control slices (presence of glucose and normal oxygenation), $50 \mathrm{mM} \mathrm{KCl}$ induced a 7-fold potentiation of Asp output and a 15-fold potentiation of that of Glu. Hypoxia and hypoglycemia alone were capable of increasing Asp and Glu release, but, as in the case of $\mathrm{D}^{-} \mathrm{H}-\mathrm{Asp}$, the ischemic challenge yielded greater effects (Table 1). 


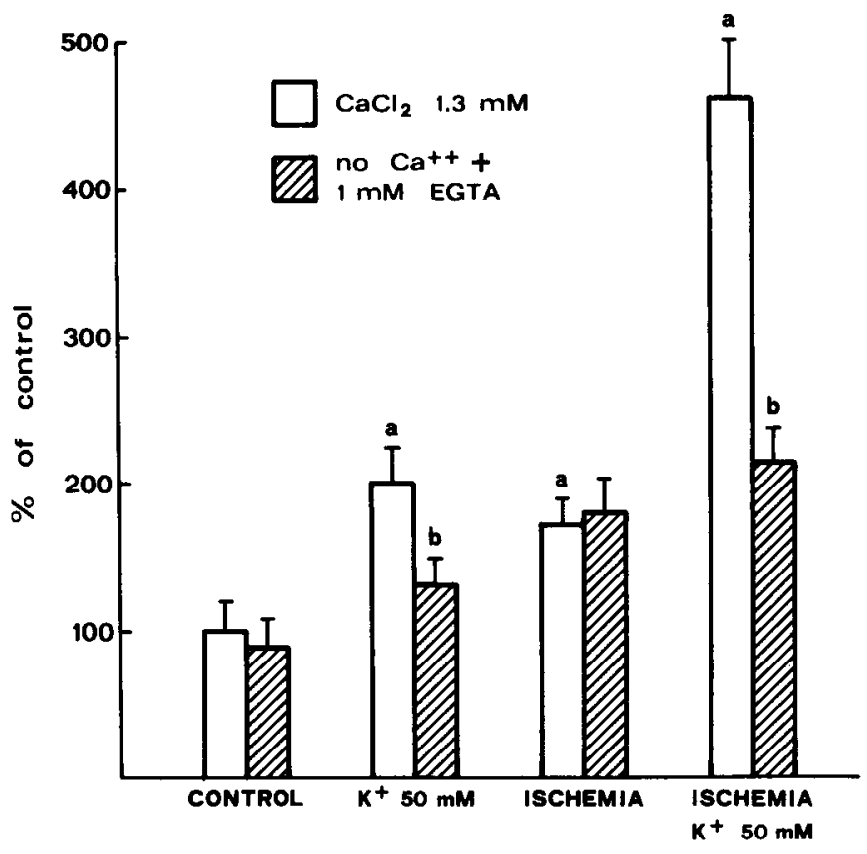

Figure 1. $\mathrm{Ca}^{2+}$ dependence of basal, stimulated $(50 \mathrm{mM} \mathrm{KCl})$, "ischemic" (incubation for $10 \mathrm{~min}$ in glucose- and $\mathrm{O}_{2}$-free medium) and of stimulated "ischemic" release of $\mathrm{D}^{-3} \mathrm{H}$-aspartate from rat hippocampal slices. $\mathrm{D}^{-}{ }^{3} \mathrm{H}$-release is expressed as a percentage of control (see Table 1 for release values of different experimental conditions in the presence of $\left.\mathrm{Ca}^{2+}\right)$. See Materials and Methods for statistical evaluation. Vertical bars are SEM of at least 5 experiments, all conducted in triplicate. ${ }^{a} p$ $<0.01$ vs control release; ${ }^{h} p<0.01$ vs release of respective model in the presence of $\mathrm{Ca}^{2+}$.

$\mathrm{Ca}^{2+}$-dependence of EAA release induced by different in vitro conditions was studied by using $\mathrm{Ca}^{2+}$-free buffers containing 1 mM EGTA. Radiolabeled and endogenous release induced by both $\mathrm{KCl}$ and ischemia plus $\mathrm{KCl}$ were partially dependent upon the presence of $\mathrm{Ca}^{2+}$ in the medium, while the ischemia-induced increase of basal release was not at all affected by the absence of $\mathrm{Ca}^{2+}$ (Figs. 1, 2).

In order to ascertain whether nonspecific lysis of the cell could be the cause of the observed outflow of labeled or endogenous amino acids, the activity of LDH, a specific cytoplasmic enzyme, was measured in the supernatant of slices treated under the experimental conditions described above. When slices were incubated alone for $20 \mathrm{~min}$ at $37^{\circ} \mathrm{C}, \mathrm{LDH}$ activity in the incubation medium was $0.64 \pm 0.05 \mathrm{U} /$ liter $(n=4)$. After $10 \mathrm{~min}$ of hypoxia, the release was $0.70 \pm 0.05$, and in the presence of $0.5 \mathrm{~mm}$ xanthine plus $20 \mathrm{mU} / \mathrm{ml} \mathrm{XOD}$, it was $0.72 \pm 0.06$ $\mathrm{U} /$ liter (not significant). The addition of Triton X-100 (0.1\%) to the incubation medium for $15 \mathrm{~min}$ increased $\mathrm{LDH}$ activity in the supernatant to $65.1 \pm 0.5 \mathrm{U} /$ liter.

\section{Effects of free radical scavengers and enzyme inhibitors on ischemia-induced $E A A$ release}

Table 2 shows that D-mannitol (1 mM), a hydroxyl radical scavenger, was able to reduce (by 64\%) the ischemia-induced increase in tritium outflow from hippocampal slices preloaded with $\mathrm{D}^{3} \mathrm{H}-\mathrm{Asp}$, when added to the incubation medium. The $\mathrm{O}_{2}^{-}$scavenger system formed by $\operatorname{SOD}(50 \mu \mathrm{g} / \mathrm{ml})$ plus catalase $(50 \mu \mathrm{g} / \mathrm{ml})$ was almost equally potent in this reducing effect (63\%). Indomethacin $(50 \mu \mathrm{M})$ and corticosterone $(50 \mu \mathrm{M})$, which are inhibitors, at different stages, of enzymatic free radical production, partially reduced this increase (by 43 and $51 \%$, respectively).

Table 2 also shows that the ischemia-induced release of endogenous Asp and Glu was reduced by the addition of different radical scavengers to the incubation medium. D-Mannitol (1 mM) was the most potent in this regard, inhibiting Asp release by $69 \%$ and Glu release by $60 \%$. The scavenger system formed by SOD $(50 \mu \mathrm{g} / \mathrm{ml})$ plus catalase $(50 \mu \mathrm{g} / \mathrm{ml})$ reduced Asp and Glu outflow by 48 and $46 \%$, respectively. The enzymatic inhibitors indomethacin $(50 \mu \mathrm{M})$ and corticosterone $(50 \mu \mathrm{M})$ caused

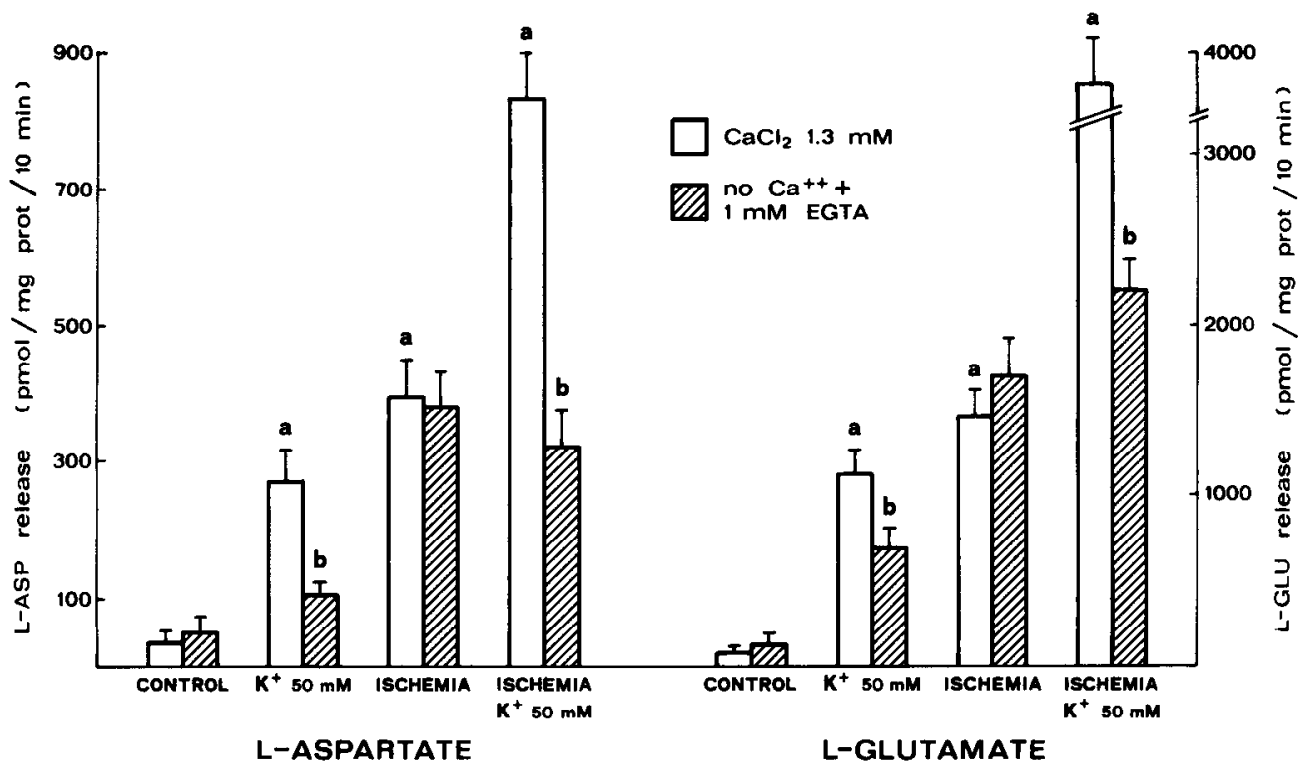

Figure 2. $\mathrm{Ca}^{2+}$ dependence of basal, stimulated, "ischemic," and stimulated "ischemic" release of endogenous Asp and Glu from hippocampal slices. See Figure 1 for experimental procedures. Values are expressed as pmol/mg protein $/ 10 \mathrm{~min}$ and are means \pm SEM of at least 5 experiments, all conducted in triplicate. See Materials and Methods for statistics. ${ }^{a} p<0.01$ vs control release; ${ }^{b} p<0.01$ vs release of respective model in the presence of $\mathrm{Ca}^{2+}$. 
Figure 3. EAA release induced by xanthine $(0.5 \mathrm{mM})$ plus XOD $(20 \mathrm{mU} /$ $\mathrm{ml}): \mathrm{Ca}^{2+}$ dependence and effects of free radical scavengers $(C$, controls; $X X, 0.5$ $\mathrm{mm}$ xanthine plus $20 \mathrm{mU} / \mathrm{ml}$ xanthine oxidase; $A, 10 \mu \mathrm{M}$ allopurinol; $M, 1 \mathrm{~mm}$ D-mannitol; $C / S, 50 \mu \mathrm{g} / \mathrm{ml}$ catalase plus $50 \mu \mathrm{g} / \mathrm{ml} \mathrm{SOD}$ ). In $\mathrm{Ca}^{2+}$-free medium, $\mathrm{Ca}^{2+}$ was omitted and 1 mm EGTA added. Results are given as a percentage of basal release (see text for control values) and are means \pm SEM of at least 4 experiments, all conducted in triplicate. See Materials and Methods for statistics. ${ }^{*}<0.05$ vs xanthine plus XOD-induced release; ${ }^{* *}<0.01$ vs xanthine plus XOD-induced release.
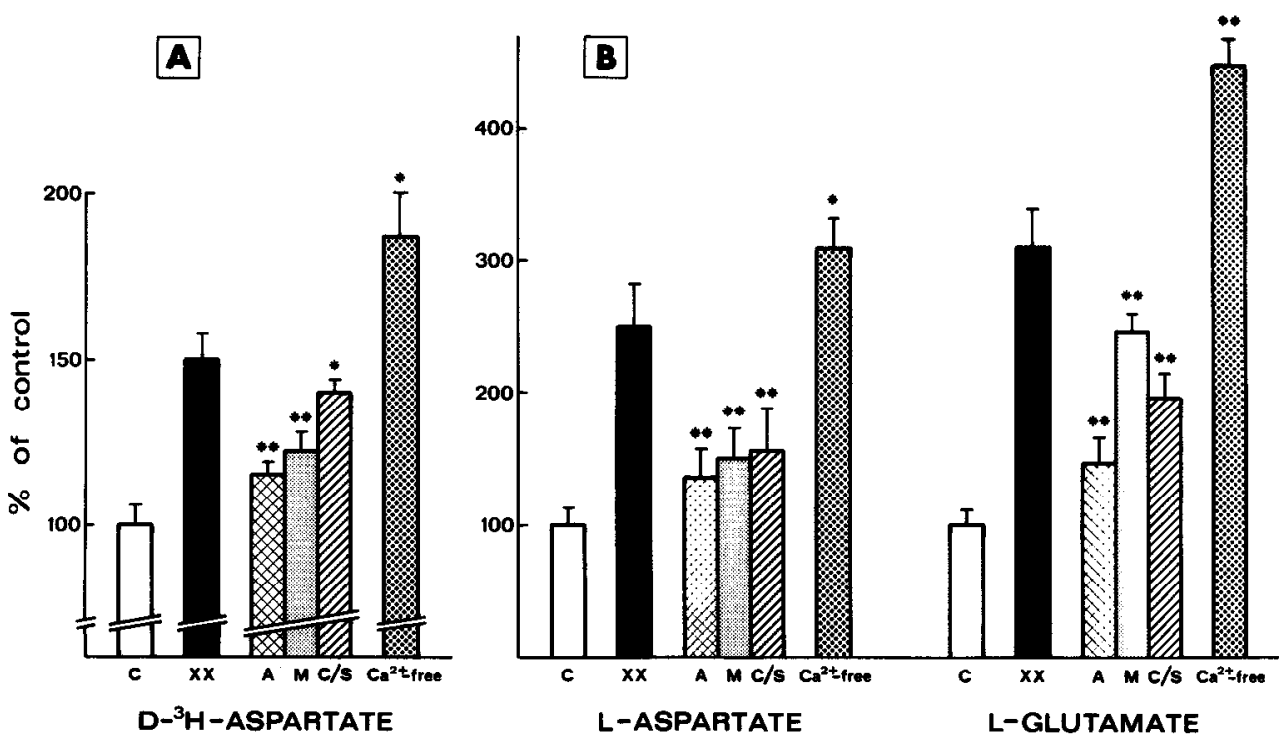

a less pronounced reduction (Table 2). None of the free radical scavengers or inhibitors tested modified the release of labeled or endogenous Asp and Glu induced by $50 \mathrm{~mm} \mathrm{KCl}$ (data not shown).

\section{Effects of xanthine plus XOD and of arachidonate plus PGS on EAA release}

When slices preloaded with $\mathrm{D}^{-3} \mathrm{H}$-Asp were exposed to xanthine $(0.5 \mathrm{~mm})$ plus XOD $(20 \mathrm{mU} / \mathrm{ml})$ for $20 \mathrm{~min}$, they released an increased amount of tritium ( $+50 \%$, Fig. 3 ). This increase was further potentiated in the absence of $\mathrm{Ca}^{2+}$ in the medium. Allopurinol $(10 \mu \mathrm{M})$, a specific inhibitor of XOD, was able to prevent almost completely $(-70 \%)$ the xanthine plus XODinduced release, which was also significantly reduced by the radical scavengers D-mannitol $(1 \mathrm{~mm})$ and SOD $(50 \mu \mathrm{g} / \mathrm{ml})$ plus catalase $(50 \mu \mathrm{g} / \mathrm{ml}$ ) (by 56 and $20 \%$ respectively; Fig. 3 ).

The xanthine plus XOD enzymatic reaction also led to a 2.5fold $\mathrm{Ca}^{2+}$-independent increase of endogenous Asp output and to a 3.2-fold increase of that of endogenous Glu (Fig. 3). This release was inhibited by $10 \mu \mathrm{M}$ allopurinol $(77 \%$ reduction for Asp and $81 \%$ for Glu), by 1 mM D-mannitol (58 and $34 \%$ reductions, respectively), and by SOD plus catalase (68 and $58 \%$, respectively).
Similarly, the output of endogenous Asp and that of Glu increased from $35.9 \pm 5.3$ and $69.4 \pm 14 \mathrm{pmol} / \mathrm{mg}$ protein, under basal conditions, to $61.4 \pm 9.3$ and $157.5 \pm 18 \mathrm{pmol} /$ $\mathrm{mg}$ protein, respectively, when the slices were incubated for 10 min in the presence of $100 \mu \mathrm{M}$ arachidonate and $500 \mathrm{mU}$ PGS $(n=4, p<0.01)$.

LDH activity was not modified in the supernatant of slices exposed to these treatments.

\section{Effects of EAA receptor antagonists on endogenous Glu and Asp release}

Table 3 shows that KYN (100-300 $\mu \mathrm{M})$, a nonselective EAA receptor antagonist (Stone and Burton, 1988) and DNQX (10$30 \mu \mathrm{M})$, a putative blocker of EAA receptors of the non- $N$-methyl-D-aspartate type (Honoré et al., 1988), when added to the "ischemic" incubation medium, werc ablc to reduce cndogenous Asp and Glu release from hippocampal slices. On the other hand, neither the NMDA receptor antagonist D,L-2-amino-5phosphonovaleric acid (AP5) nor the selective glycine antagonist 7-Cl-kynurenate (7-Cl-KYN) (Kemp et al., 1988) at fully active concentrations significantly reduced ischemia-induced EAA release.

Table 2. Effects of different free radical scavengers and inhibitors on simulated ischemia-induced EAA release in vitro

\begin{tabular}{|c|c|c|c|c|c|c|}
\hline \multirow[b]{2}{*}{ Condition } & \multicolumn{6}{|l|}{ Release } \\
\hline & D- ${ }^{3} \mathrm{H}-\mathrm{Asp}$ & $(\%)$ & L-Asp & $(\%)$ & L-Glu & $(\%)$ \\
\hline Control & $14.0 \pm 0.4$ & $(100)$ & $37.1 \pm 8.6$ & $(100)$ & $72.6 \pm 15$ & $(100)$ \\
\hline "Ischemia" & $24.5 \pm 1.9$ & $(175)$ & $395.2 \pm 49$ & $(1065)$ & $1465 \pm 135$ & $(2017)$ \\
\hline "Ischemia" " 1 mм D-mannitol & $17.8 \pm 1.8^{b}$ & (127) & $148.1 \pm 17^{b}$ & (399) & $629.8 \pm 73^{b}$ & $(867)$ \\
\hline \multicolumn{7}{|l|}{ "Ischemia" + SOD $(50 \mu \mathrm{g} / \mathrm{ml})$} \\
\hline+ catalase $(50 \mu \mathrm{g} / \mathrm{ml})$ & $17.9 \pm 2.0^{b}$ & $(128)$ & $223.3 \pm 25^{b}$ & $(602)$ & $824.8 \pm 94^{b}$ & $(1136)$ \\
\hline "Ischemia" $+50 \mu \mathrm{M}$ indomethacin & $20.0 \pm 3.0^{\alpha}$ & (143) & $334.3 \pm 31$ & (901) & $1298 \pm 131$ & (1788) \\
\hline "Ischemia" $+50 \mu \mathrm{M}$ corticosterone & $19.2 \pm 2.6^{a}$ & $(137)$ & $312.9 \pm 28^{a}$ & $(843)$ & $1242 \pm 125^{a}$ & (1711) \\
\hline
\end{tabular}

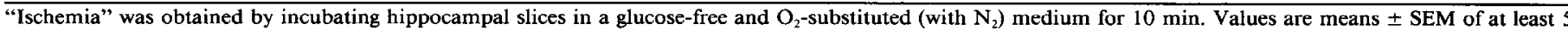
experiments, all conducted in triplicate. See legend to Table 1 and Materials and Methods for experimental and statistical procedures.

${ }^{a} p<0.05$ vs ischemia alone.

${ }^{b} p<0.01$ vs ischemia alone. 


\section{Discussion}

The aim of our study was to clarify the relationship between 2 widely studied pathogenetic events linking hypoxic or ischemic brain damage to the death of neurons: production of free radicals (Siesjo, 1981; Raichle, 1983; Braughler and Hall, 1989) and abnormal extracellular concentrations of EAA (Meldrum, 1985; Rothman and Olney, 1986; Choi, 1988a).

Our first step was to develop a satisfactory in vitro model of ischemia, in which EAA release could be detected. Similar models have been reported previously (Bosley et al., 1983; Hauptman et al., 1984; Drejer et al., 1985). Initial results showed that slices from rat hippocampi, not exposed to depolarizing solutions, released large amounts of $\mathrm{D}^{-3} \mathrm{H}$-Asp and of endogenous Asp and Glu only when incubated with a medium mimicking in vivo ischemic conditions (lack of both glucose and $\mathrm{O}_{2}$ ). A much more pronounced outflow of EAA was observed when hypoxic, hypoglycemic, or ischemic conditions were tested in the presence of $50 \mathrm{mM} \mathrm{KCl}$. However, we focused our attention on the nondepolarized ischemic approach because the simultaneous occurrence of both oxygen and glucose deprivation closely resembles what happens during stroke; because, in this case, the appearance of EAA in the medium was unaffected by the extracellular concentrations of $\mathrm{Ca}^{2+}$; and because it was not associated with possible nonspecific cellular lysis, since the activity of the cytoplasmic enzyme LDH was not increased in the incubation medium. In our "ischemic" model, this efflux of EAA could not be ascribed simply to the rise in extracellular $\mathrm{K}^{+}$which has been shown during ischemia (Hansen, 1985), since the addition of $\mathrm{KCl}$ to the "ischemic" slices produced a further increase in EAA outflow, which was not lower than that induced by $\mathrm{KCl}$ in control slices. Furthermore, the $\mathrm{KCl}$-induced EAA output was $\mathrm{CA}^{2+}$-dependent, while the phenomenon we studied was not (see also Sànchez-Prieto and Gonzàlez, 1988; Ikeda et al., 1989).

The observation that the "ischemia"-induced appearance of EAA in the incubation medium could be significantly reduced by compounds such as D-mannitol, indomethacin, corticosterone, and the enzymes catalase and SOD, which have in common the ability to "scavenge" or reduce the formation of oxygen-derived free radicals, demonstrated that these active molecular species were involved in the elevation of EAA concentrations in the extracellular medium. A direct demonstration

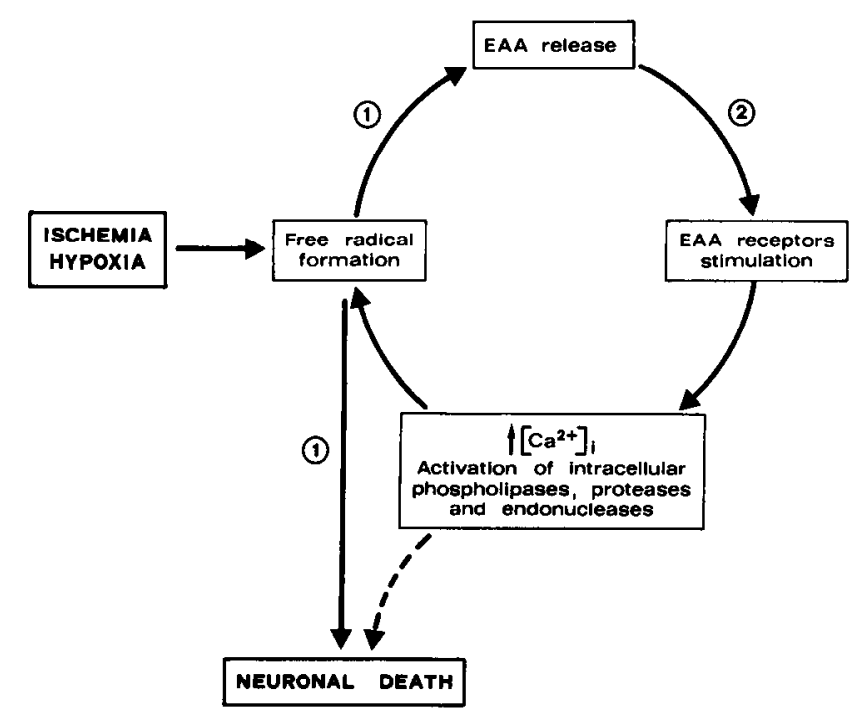

Figure 4. Hypothetical vicious circle illustrating the possible mutual cooperation between free radical formation and EAA release in the pathogenesis of neuronal damage induced by hypoxia and ischemia. Toxic free radicals, formed following the reduction in blood flow or oxygen supply to the brain promote the release of EAA, which in turn may exert their toxic effects by interacting with specific receptors. Stimulation of EAA receptors increases intracellular $\mathrm{Ca}^{2+}$ concentrations, resulting in both neuronal damage and further production of free radicals (Choi, 1988b; Siesjo and Bengtsson, 1989). This gives the possibility of starting another cycle. It is possible to interrupt this circle by using $(I)$ free radical scavengers and enzyme inhibitors or (2) EAA receptor antagonists. See text for further discussion.

of this hypothesis was obtained by showing that the incubation of hippocampal slices with systems leading to free radical formation (xanthine plus XOD or arachidonate plus PGS) resulted in an increase of the release of both $\mathrm{D}^{-3} \mathrm{H}$-Asp and endogenous Asp and Glu. The possibility that free radical formation may release intracellular active components has been previously reported (Ohmori et al., 1980; Mannaioni and Masini, 1988).

The formation of free radicals during hypoxic or ischemic states is widely accepted (Braughler and Hall, 1989; Hall and Braughler, 1989). It has been proposed that they are formed mainly during the reperfusion of previously ischemic tissues,

\begin{tabular}{|c|c|c|c|c|}
\hline Condition & L-Asp & $\%$ & L-Glu & $\%$ \\
\hline Control & $38 \pm 8$ & - & $75 \pm 15$ & - \\
\hline "Ischemia" & $392 \pm 40$ & $(100)$ & $1500 \pm 200$ & $(100)$ \\
\hline Ischemia + KYN $100 \mu \mathrm{M}$ & $350 \pm 50$ & $(89)$ & $1380 \pm 100$ & $(92)$ \\
\hline Ischemia + KYN $300 \mu \mathrm{M}$ & $290 \pm 20^{a}$ & $(70)$ & $1070 \pm 110^{a}$ & $(71)$ \\
\hline Ischemia $+7 \mathrm{Cl}-\mathrm{KYN} 10 \mu \mathrm{M}$ & $350 \pm 90$ & $(92)$ & $1520 \pm 150$ & $(101)$ \\
\hline Ischemia $+7 \mathrm{Cl}-\mathrm{KYN} 50 \mu \mathrm{M}$ & $330 \pm 40$ & $(87)$ & $1490 \pm 120$ & (99) \\
\hline Ischemia + AP5 $50 \mu \mathrm{M}$ & $350 \pm 35$ & (89) & $1350 \pm 130$ & (90) \\
\hline Ischemia + AP5 $100 \mu \mathrm{M}$ & $370 \pm 40$ & (94) & $1425 \pm 140$ & (95) \\
\hline Ischemia + DNQX $30 \mu \mathrm{M}$ & $270 \pm 30^{a}$ & (69) & $1100 \pm 80^{a}$ & (73) \\
\hline Ischemia + DNQX $100 \mu \mathrm{M}$ & $261 \pm 15^{a}$ & (66) & $1080 \pm 100^{a}$ & (72) \\
\hline
\end{tabular}

\footnotetext{
Means \pm SE of at least 4 experiments conducted in duplicate as picomol/mg protein $/ 10 \mathrm{~min}$ and percentages of the "ischemia"-induced release are given. See Table 1 and Materials and Methods for experimental and statistical procedures.

${ }^{a} p<0.01$ vs ischemia alone.
} 
by means of reactions involving XOD (McCord, 1985), PGS (Rehncrona et al., 1982; Kontos and Wei, 1986) or mitochondrial ubisemiquinone (Turrens et al., 1985; Patole et al., 1986). However, free radicals may also be formed during incomplete ischemia or even during complete ischemia or anoxia. In these cases, $\mathrm{O}_{2}$ brought in by collateral vessels (Flamm et al., 1978), the "univalent leak" of $\mathrm{O}_{2}^{-}$from mitochondria (Del Maestro, 1980), and the possibility of free radical formation even when tissues contain only $5 \%$ of normal $\mathrm{O}_{2}$ levels (Demopoulos et al., 1980) may be of importance.

From these studies it is not possible to understand which might be the source of free radicals in our ischemic model. It is likely that those mechanisms which are operative during incomplete or complete ischemia are also important in our experimental conditions. In any case, our experiments utilizing an exogenous source of free radicals (xanthine plus XOD or arachidonic acid plus PGS) clearly demonstrate that they are indeed able to induce the outflow of EAA. Moreover, previous experiments from our group had shown that these enzymatic reactions were also able to release ${ }^{3} \mathrm{H}$-noradrenaline from preloaded slices (Pellegrini-Giampietro et al., 1988). Altogether, these data suggest that free radicals, formed either under simulated ischemic conditions or by enzymatic reaction, lead to a nonspecific leakage of neurotransmitters.

It has been previously shown that EAA receptor agonists may promote enzymatic reactions leading to free radical production (Dumuis ct al., 1988) and that excitotoxin-induced neuronal damage may be reduced by free radical scavengers (Dykens et al., 1987). This led us to hypothesize the existence of a vicious circle, in which free radical formation and EAA release could affect each other in the generation and propagation of ischemic neuronal death (Fig. 4). This proposed mechanism could account for the efficacy of free radical scavengers in preventing both EAA release (our data) and excitotoxin-mediated functional and morphological impairment (Lassmann et al., 1984; Baran et al., 1987; Dykens et al., 1987) (Fig. 4, point 1). In support of the existence of such a vicious circle stand also the experiments shown in Table 3 showing that EAA receptor antagonists such as KYN and DNQX reduced the "ischemia"induced EAA output (Fig. 4, point 2). In the model here described, the EAA receptors involved appear to be of non-NMDA type, since AP5, a typical NMDA antagonist, or 7-Cl-KYN, a compound able to antagonize the strychnine-insensitive glycine site associated to the NMDA receptor ion channel complex, failed to reduce the EAA release in ischemic conditions.

\section{References}

Andiné, P., A. Lehmann, K. Ellren, E. Wennberg, I. Kjellmer, T. Nielsen, and $H$. Hagberg (1988) The excitatory amino acid antagonist kynurenic acid administered after hypoxic-ischemia in neonatal rats offers neuroprotection. Neurosci. Lett. 90: 208-212.

Baran, H., H. Lassmann, G. Sperk, F. Seitelberger, and O. Hornykiewicz (1987) Effect of mannitol treatment on brain neurotransmitter markers in kainic acid-induced epilepsy. Neuroscience 21: 679-684.

Benveniste, H., J. Drejer, A. Schousboe, and N. H. Diemer (1984) Elevation of the extracellular concentrations of glutamate and aspartate in rat hippocampus during transient cerebral ischemia monitored by intracerebral microdialysis. J. Neurochem. 43: 1369-1374.

Bosley, T. M., P. L. Woodhams, R. D. Gordon, and R. Balazs (1983) Effects of anoxia on the stimulated release of amino acid neurotransmitters in the cerebellum in vitro. J. Neurochem. 40: 189-201.

Braughler, J. M., and E. D. Hall (1989) Central nervous system trauma and stroke. I. Biochemical considerations for oxygen radical formation and lipid peroxidation. Free Radic. Biol. Med. 6: 289-301.
Cao, W., J. M. Carney, A. Duchon, R. A. Floyd, and M. Chevion (1988) Oxygen free radical involvement in ischemia and repcrfusion injury to brain. Neurosci. Lett. $88: 233-238$.

Choi, D. W. (1988a) Glutamate neurotoxicity and diseases of the nervous system. Neuron $1: 623-634$.

Choi, D. W. (1988b) Calcium-mediated neurotoxicity: Relationship to specific channel types and role in ischemic damage. Trends Neurosci. 11: 465-469.

Clark, G. D., and S. M. Rothman (1987) Blockade of excitatory amino acid receptors protects anoxic hippocampal slices. Neuroscience 21 : $665-671$.

Connick, J. H., and T. W. Stone (1988) Excitatory amino acid antagonists and endogenous aspartate and glutamate release from rat hippocampal slices. Br. J. Pharmacol. 93: 863-867.

Corradetti, R., G. Moneti, F. Moroni, G. Pepeu, and A. Wieraszko (1983) Electrical stimulation of the stratum radiatum increases the release and neosynthesis of aspartate, glutamate and $\gamma$-aminobutyric acid in rat hippocampal slices. J. Neurochem. 41: 1518-1525.

Del Maestro, R. F. (1980) An approach to free radicals in medicine and biology. Acta Physiol. Scand. Suppl. 492: 153-168.

Demopoulos, H. B., E. S. Flamm, D. D. Pietronigro, and M. L. Seligman (1980) The free radical pathology and the microcirculation in the major central nervous system disorders. Acta Physiol. Scand. Suppl. 492: 91-119.

Drejer, J., H. Benveniste, N. H. Diemer, and A. Schousboe (1985) Cellular origin of ischemia-induced glutamate release from brain tissue in vivo and in vitro. J. Neurochem. 45: 145-151.

Dumuis, A., M. Sebben, L. Haynes, J.-P. Pin, and J. Bockaert (1988) NMDA receptors activate the arachidonic acid cascade system in striatal neurons. Nature 336: 68-70.

Dykens, J. A., A. Stern, and E. Trenkner (1987) Mechanism of kainate toxicity to cerebellar neurons in vitro is analogous to reperfusion tissue injury. J. Neurochem. 49: 1222-1228.

Erecinska, M., D. Nelson, D. F. Wilson, and I. A. Silver (1984) Neurotransmitter amino acids in the CNS. I. Regional changes in amino acid levels in rat brain during ischemia and reperfusion. Brain Res. 304: 9-22.

Flamm, E. S., H. B. Demopoulos, M. L. Seligman, G. R. Poser, and J. Ransohoff (1978) Free radicals in cerebral ischemia. Stroke 9:445451.

Gill, R., A. C. Foster, and G. N. Woodruff (1987) Systemic administration of MK-801 protects against ischemia-induced hippocampal neurodegeneration in the gerbil. J. Neurosci. 7: 3343-3349.

Globus, M. Y.-T., R. Busto, W. D. Dietrich, E. Martinez, I. Valdes, and M.D. Ginsberg (1988) Effect of ischemia on the in vivo release of striatal dopamine, glutamate and $\gamma$-aminobutyric acid studied by intracerebral microdialysis. J. Neurochem. 51: 1455-1464.

Goldberg, M. P., J. H. Weiss, P.-C. Pham, and D. W. Choi (1987) $\mathrm{N}$-methyl-D-aspartate receptors mediate hypoxic neuronal injury in cortical culture. J. Pharmacol. Exp. Ther. 243: 784-791.

Hagberg, H., A. Lehmann, M. Sandberg, B. Nystrom, I. Jacobson, and A. Hamberger (1985) Ischemic-induced shifts of inhibitory and excitatory amino acids from intra- to extracellular compartments. $\mathbf{J}$. Cereb. Blood Flow Metab. 5: 413-419.

Hall, E. D., and J. M. Braughler (1989) Central nervous system trauma and stroke. II. Physiological and pharmacological evidence for involvement of oxygen radicals and lipid peroxidation. Free Radic. Biol. Med. 6: 303-313.

Hansen, A. J. (1985) Effects of anoxia on ion distribution in the brain. Physiol. Rev. 65: 101-148.

Hauptman, M., D. Nelson, D. F. Wilson, and Erecinska M. (1984) Neurotransmitter amino acids in the CNS. II. Some changes in amino acid levels in rat brain synaptosomes during and after in vitro anoxia and simulated ischemia. Brain Res. 304: 23-35.

Honoré, T., S. N. Davies, J. Drejer, E. J. Fletcher, P. Jacobsen, D. Lodge, and F. E. Nielsen (1988) Quinoxalinediones: Potent competitive non-NMDA glutamate receptor antagonists. Science 241 : 701703.

Ikeda, M., T. Nakazawa, K. Abe, T. Kaneko, and K. Yamatsu (1989) Extracellular accumulation of glutamate in the hippocampus induced by ischemia is not calcium dependent-in vitro and in vivo evidence. Neurosci. Lett. 96: 202-206.

Itoh, T., M. Kawakami, Y. Yamauchi, S. Shimizu, and M. Nakamura (1986) Effect of allopurinol on ischemia and reperfusion-induced cerebral injury in spontancous hypcrtensive rats. Stroke 17: 12841287. 
Kellogg, E. W. III, and I. Fridovich (1977) Liposome oxidation and erythrocyte lysis by enzymatically generated superoxide and hydrogen peroxide. J. Biol. Chem. 252:6721-6728.

Kemp, J. A., A. C. Foster, P. D. Leeson, T. Priestly, R. Tridgett, L. L. Iversen, and G. N. Woodruff (1988) 7-Chloro-kynurenic acid is a selective antagonist at the glycine modulatory site of the N-methylD-aspartate receptor complex. Proc. Natl. Acad. Sci. USA 85: 65476550.

Kochhar, A., J. A. Zivin, P. D. Lyden, and V. Mazzarella (1988) Glutamate antagonist therapy reduces neurologic deficits produced by focal central nervous system ischemia. Arch. Neurol. 45: 148-153.

Kontos, H. A., and E. P. Wei (1986) Superoxide production in ex perimental brain injury. J. Neurosurg. 64: 803-807.

Lassmann, H., U. Petsche, K. Kitz, H. Baran, G. Sperk, F. Seitelberger, and O. Hornykiewicz (1984) The role of brain edema in epileptic brain damage induced by systemic kainic acid injection. Neuroscience 13: 691-704.

Leach, M. J., K. J. Hollox, R. A. O'Donnell, and A. A. Miller (1988) Hippocampal NMDA/phencyclidine receptor binding sites are reduced following forebrain ischaemia in the gerbil. Eur. J. Pharmacol. 152: 189-192.

Lowry, O. H., N. J. Rosebrough, A. L. Farr, and R. J. Randall (1951) Protein measurement with the folin-phenol reagent. J. Biol. Chem. 193: 265-275.

Mannaioni, P. F., and E. Masini (1988) The release of histamine by free radicals. Free Radic. Biol. Med 5: 177-197.

McCord, J. M. (1985) Oxygen-derived free radicals in postischemic tissue injury. N. Engl. J. Med. 312: 159-163.

Meldrum, B. (1985) Excitatory amino acids and anoxic/ischemic brain damage. Trends Neurosci. $8: 47-48$

Moroni, F., C. Bianchi, S. Tanganelli, G. Moneti, and L. Beani (1981) The release of $\gamma$-aminobutyric acid, glutamate, and acetylcholine from striatal slices: A mass-fragmentographic study. J. Neurochem. 36: 1691-1697.

Ohmori, H., I. Yamamoto, M. Akagi, and K. Tasaka (1980) Properties of hydrogen peroxide-induced histamine release from rat mast cells. Biochem. Pharmacol. 28: 741-745.

Patole, M. S., A. Swaroop, and T. Ramasarma (1986) Generation of $\mathrm{H}_{2} \mathrm{O}_{2}$ in brain mitochondria. J. Neurochem. 47: 1-8.

Pellegrini-Giampietro, D. E., G. Cherici, M. Alesiani, V. Carla, and F. Moroni (1988) Excitatory amino acid release from rat hippocampal slices as a consequence of free-radical formation. J. Neurochem. 51 1960-1963.

Raichle, M. E. (1983) The pathophysiology of brain ischemia. Ann. Neurol. 13: 2-10.

Rehncrona, S., E. Westerberg, B. Akesson, and B. K. Siesjo (1982) Brain cortical fatty acids and phospholipids during and following complete and severe incomplete ischemia. J. Neurochem. 38: 84-93.

Rothman, S. (1984) Synaptic release of excitatory amino acid neurotransmitters mediates anoxic neuronal death. J. Neurosci. 4: 1884 1891.
Rothman, S. M., and J. W. Olney (1986) Glutamate and the pathophysiology of hypoxic-ischemic brain damage. Ann. Neurol. 19: 105111 .

Rothman, S. M., and J. W. Olney (1987) Excitotoxicity and the NMDA receptor. Trends Neurosci. 10: 299-302.

Sanchez-Prieto, J., and P. Gonzalez (1988) Occurrence of a large $\mathrm{Ca}^{2+}$ independent release of glutamate during anoxia in isolated nerve terminals (synaptosomes). J. Neurochem. 50:1322-1324.

Sasaki, T., T. Nakagomi, T. Kirino, A. Tamura, M. Noguchi, I. Saito, and $\mathrm{K}$. Takakura (1988) Indomethacin ameliorates ischemic neuronal damage in the gerbil hippocampal CA, sector. Stroke 19: 13991403.

Siesjo, B. K. (1981) Cell damage in the brain: A speculative synthesis. J. Cereb. Blood Flow Metab. 1: 155-185.

Siesjo, B. K., and F. Bengtsson (1989) Calcium fluxes, calcium antagonists, and calcium-related pathology in brain ischemia, hypoglycemia, and spreading depression: A unifying hypothesis. J. Cereb. Blood Flow Metab. 9: 127-140.

Simon, R. P., J. H. Swan, T. Griffiths, and B. S. Meldrum (1984) Blockade of N-methyl-D-aspartate receptors may protect against ischemic damage in the brain. Science 226: 850-852.

Smith, D. S., S. Rehncrona, and B. K. Siesjo (1980) Barbiturates as protective agents in brain ischemia and as free radical scavengers in vitro. Acta Physiol. Scand. Suppl. 492: 129-134.

Smith, M.-L., R. N. Auer, and B. K. Siesjo (1984) The density and distribution of ischemic brain injury in the rat following two to ten minutes of forebrain ischemia. Acta Neuropathol. (Berl.) 64:319332.

Stone, T. W., and N. R. Burton (1988) NMDA receptors and ligands in the vertebrate CNS. Prog. Neurobiol. 30: 333-368.

Taylor, M. D., G. C. Palmer, and A. S. Callahan (1984) Protective action by methylprednisolone, allopurinol and indomethacin against stroke-induced damage to adenylate cyclase in gerbil cerebral cortex. Stroke 15: 329-335.

Taylor, M. D., T. K. Mellert, J. L. Parmentier, and L. J. Eddy (1985) Pharmacological protection of reoxygenation damage to in vitro brain slice tissue. Brain Res. 347: 268-273.

Turrens, J. F., A. Alexandre, and A. L. Lehninger (1985) Ubisemiquinone is the electron donor for superoxide formation by complex III of heart mithocondria. Arch. Biochem. Biophys. 237: 408-414.

Vassault, A. (1983) Lactate dehydrogenase. UV-method with pyruvate and NADH. In Methods of Enzymatic Analysis, Vol. 3: Enzymes I: Oxidoreductases, Transferases, H. U. Bergmeyer, ed., pp. 118-126, Verlag Chemie, Weinheim, FRG.

Wallenstein, S., C. L. Zucker, and J. L. Fleiss (1980) Some statistical methods useful in circulation research. Circ. Res. 47: 1-47.

Westerberg, E., D. T. Monaghan, C. W. Cotman, and T. Wieloch (1987) Excitatory amino acid receptors and ischemic brain damage in the rat. Neurosci. Lett. 73: 119-124. 